\title{
RESEARCH
}

Open Access

\section{Ultrasound inflammatory parameters and Treg/Th17 cell profiles in established rheumatoid arthritis}

Aline Defaveri do Prado ${ }^{1,2^{*}}$, Melissa Cláudia Bisi', Deise Marcela Piovesan ${ }^{1}$, Markus Bredemeier², Talita Siara Baptista ${ }^{3}$, Laura Petersen ${ }^{3}$, Moises Evandro Bauer ${ }^{3}$, Inês Guimarães da Silveira ${ }^{1}$, José Alexandre Mendonça ${ }^{4}$ and Henrique Luiz Staub ${ }^{1}$

\begin{abstract}
Background: Imbalance and disfuntion in regulatory T-cells (Tregs) and IL-17 producer lymphocytes (Th17) have been implicated in the pathogenesis of rheumatoid arthritis (RA). Gray scale synovial proliferation (GS), power Doppler signal (pD) and bone erosions seen on high resolution muskuloskeletal ultrasound (MSUS) are hallmarks of destructive articular disease.

Objective: To evaluate the association of peripheral Tregs and Th17 with MSUS findings in RA.

Methods: RA patients (1987 ACR criteria) treated with disease-modifying antirheumatic drugs (DMARDs) were included. Lymphocytes were isolated and immunophenotyped by flow cytometry to investigate regulatory FoxP3+ T cells and IL-17+ cells. MSUS (MyLab 60, Esaote, Genova, Italy, linear probe 6-18 MHz) was performed on hand joints, and a 10-joint US score was calculated for each patient.

Results: Data on lymphocytes subsets were avaiable for 90 patients. The majority of patients were Caucasian women with a median disease duration of 6 years (interquartile range: 2-13 years). Mean DAS28 was 4.28 (SD \pm 1.64$)$ and mean HAQ score was 1.11 (SD \pm 0.83 ).

There was no significant correlation of 10-joint GS score ( $\mathrm{rS}=0.122$, 95\% Cl: -0.124 to $0.336, P=0.254$ ) and 10-joint $\mathrm{pD}$ score $(\mathrm{rS}=0.056,95 \% \mathrm{Cl}:-0.180$ to $0.273, P=0.602)$ with the mean percentage of peripheral Treg cells. Also, 10-joint GS score ( $\mathrm{rS}=0.083,95 \% \mathrm{Cl}:-0.125$ to $0.302, P=0.438$ ) and 10 -joint $\mathrm{pD}$ score 10 ( $\mathrm{rS}=-0.060$, 95\% Cl: 0.271 to $0.150, P=0.575)$; did not correlate to Th17 profile. No association of bone erosions on MSUS with Treg and Th17 profiles ( $P=0.831$ and $P=0.632$, respectively) was observed.

Conclusion: In this first study addressing MSUS features and lymphocytes subtypes in established RA, data did not support an association of circulating Tregs and Th17 lymphocytes with inflammatory and structural damage findings on MSUS.
\end{abstract}

\footnotetext{
* Correspondence: adprado@gmail.com

${ }^{1}$ Rheumatology Service, Pontifícia Universidade Católica do Rio Grande do

Sul (PUCRS), Ipiranga Avenue, 6690 room 220, Porto Alegre, RS CEP

90610-000, Brazil

${ }^{2}$ Rheumatology Service, Hospital Nossa Senhora da Conceição - Grupo

Hospitalar Conceição (GHC), Av. Francisco Trein, 596 - 2nd floor, Porto

Alegre, RS CEP 91350-200, Brazil

Full list of author information is available at the end of the article
}

(c) The Author(s). 2019 Open Access This article is distributed under the terms of the Creative Commons Attribution 4.0 International License (http://creativecommons.org/licenses/by/4.0/), which permits unrestricted use, distribution, and reproduction in any medium, provided you give appropriate credit to the original author(s) and the source, provide a link to the Creative Commons license, and indicate if changes were made. The Creative Commons Public Domain Dedication waiver (http://creativecommons.org/publicdomain/zero/1.0/) applies to the data made available in this article, unless otherwise stated. 


\section{Introduction}

Rheumatoid arthritis (RA) is a chronic autoimmune disease characterized by polyarthritis leading to synovial proliferation, pannus formation, bone erosions and joint deformities [1]. Besides the major role of cytokines in the development and progression of the disease, specially TNF-alpha and interleukins (IL) [2], regulatory $\mathrm{T}$ cells (Tregs) and lymphocytes producers of IL-17 (Th17) imbalance and disfuntion have also been implicated in the pathogenesis of rheumatoid arthritis (RA) [3].

In recent years, high-resolution musculoskeletal ultrasound (MSUS) has been widely used in clinical rheumatology practice, since it has demonstrated consistent and reproducible results among trained rheumatologists [4]. Synovial proliferation seen on gray scale ultrasound (GS) and synovial power Doppler (pD) signal are characteristics of joint inflammation. The usefulness of MSUS in the setting of RA patient assistance, especially for the detection of subclinical synovitis, RA relapse and structural progression has already been scientifically proved and is included in the current management of rheumatoid arthritis $[5,6]$.

The linkage between RA inflammatory cells and mediators with articular ultrasonographic abnormalities has been an interesting area of investigation. The association of plasma IL-6, a major inflammatory cytokine, with joint sonographic findings, specially power Doppler, was demonstrated in early RA [7] and established disease [8]. Plasma IL-17 was associated with joint $\mathrm{pD}$ and gray scale synovitis in the hands of RA patients [9]. However, the relationship of MSUS findings with circulating suppressive or inflammatory $\mathrm{T}$ cell subtypes has not been addressed so far. In the current study, we evaluate the association of MSUS parameters with the $\mathrm{T}$ regulatory (Treg) and Th17 cell profiles.

\section{Methods}

RA outpatients (classified according to the 1987 American College of Rheumatology criteria) treated exclusively with non-biologic disease-modifying anti-rheumatic drugs (DMARDs) were consecutively included in this prospective cross-sectional study.

MSUS examination was performed using a high resolution machine (MyLab 60, Esaote, Genova, Italy) and a linear high-frequency probe $(6-18 \mathrm{MHz})$ by one of two sonography-trained rheumatologists unware of clinical and laboratory data. Details of MSUS assessment and interobserver agreement is described elsewhere [7]. A single Rheumatologist (DMP) evaluated disease activity using the Disease Activity Score in 28 joints (DAS28) and applied the Health Assessment Questionnaire (HAQ) before MSUS.

A blood sample was taken just before clinical and sonographic evaluation and immediately used for lymphocytes identification. Peripheral lymphocytes were isolated and immunophenotyped by flow cytometry to investigate regulatory FoxP3+ T cells and IL-17+ cells using a commercially available Human Th-17/Treg Phenotyping Kit (BD Biosciences, San Jose, CA, USA), according to manufacturer's instructions.

All blood samples were collected at 8:00 AM and clinical and ultrasound evaluations were performed in the morning, between 8:30 and 11:00 AM.

\section{Statistical analysis}

Statistical analyses were performed using SPSS for Windows, version 20.0. Between-group comparisons involving non-normal quantitative variables were performed using the Mann-Whitney or Kruskal-wallis tests, and correlations were assessed using Spearman's rank $\left(r_{S}\right)$. Confidence intervals for correlations were estimated using the Bootstrapping method with 1000 iteractions. Two-tailed $P$ values less than or equal to 0.05 were considered statistically significant.

\section{Results}

We evaluated iniatially 101 RA patients, and data on lymphocytes subsets were avaiable for 90 patients (samples from 11 had to be excluded due to technical problems during cytometry) whose clinical and demographic features are described in Table 1. Among them, Caucasian women predominated, with a median disease duration of 6 years (interquartile range: 2-13 years). Mean DAS28 was 4.28 (SD \pm 1.64$)$ and mean HAQ score was 1.11 ( $\mathrm{SD} \pm 0.83)$. More than $80 \%$ of patients were on methotrexate. Moderate disease activity according to DAS28 was observed in the majority of the sample (67.8\%), 32.2\% had high and $28.9 \%$ had low disease activity (LDA). Only $14.4 \%$ of patients were on DAS28 remission.

There was no significant correlation of 10-joint GS score $\left(r_{S}=0.122,95 \% C I:-0.124\right.$ to $\left.0.336, P=0.254\right)$ and 10-joint $\mathrm{pD}$ score $\left(\mathrm{r}_{\mathrm{S}}=0.056,95 \% \mathrm{CI}\right.$ : -0.180 to

Table 1 Clinical and demographic features of the patients $(n=90)$

\begin{tabular}{ll}
\hline & $\begin{array}{l}\text { Number of patients } \\
\text { (absolute and percent) }\end{array}$ \\
\hline Female gender & $72(80 . \%)$ \\
Caucasians & $77(85.6 \%)$ \\
Positive Rheumatoid Factor & $64(63.4 \%)$ \\
Current smoker & $12(13.3 \%)$ \\
Fibromyalgia- associated with RA $_{\text {Methotrexate }}{ }^{a}$ & $4(4.4 \%)$ \\
Leflunomide $^{a}$ & $74(82.2 \%)$ \\
Hydroxychloroquine $^{a}$ & $37(41.1 \%)$ \\
Sulfasalazine $^{a}$ & $24(26.7 \%)$ \\
\hline
\end{tabular}

${ }^{\text {aCurrent use }}$ 
$0.273, P=0.602)$ with the mean percentage of peripheral Treg cells (Fig. 1). Also, 10-joint GS score $\left(\mathrm{r}_{\mathrm{S}}=0.083\right.$, 95\% CI: -0.125 to $0.302, P=0.438)$ and 10 -joint $\mathrm{pD}$ score $10\left(\mathrm{r}_{\mathrm{S}}=-0.060,95 \% \mathrm{CI}:-0.271\right.$ to $0.150, P=$ 0.575; Additional file 1: Figure S1) did not correlate to Th17 profile. There was also no association of MSUS abnormalities in right wrist (one of the most frequently affected joints in RA) with Treg or Th-17 lymphocytes percentage in peripheral blood $(P=0.459$ and $P=0.418$, respectively; Additional file 2: Figure S2 and Additional file 3: Figure S3). In addition, no association of bone erosions on MSUS with Treg and Th17 profiles ( $P=0.831$ and $P=0.632$, respectively) was observed.

In secondary analyses, the mean percentage of peripheral Treg cells was associated with level of disease activity $(p=0.020)$; patients with LDA presented the highest percentage (Additional file 4: Figure S4). There was also a trend for negative association of DAS28 and Treg cells percentage $\left(r_{S}=-0.18,95 \%\right.$ CI: -0.380 to $0.034, P=0.088$ ). Th17 cells tended to be higher in LDA (Additional file 5: Figure S5), but there was no evidence of significant correlation of DAS28 (taken as a continuous variable) with Th17 lymphocytes percentage $\left(\mathrm{r}_{\mathrm{S}}=-0.89\right.$, $95 \%$ CI: -0.301 to $0.139, P=0.402$ ).

\section{Discussion}

To the best of our knowledge, this is the first study addressing the relation of MSUS features with blood lymphocytes subtypes in RA. Our sample was composed of established RA patients on non-biologic DMARDs. No significant association of MSUS abnormalities with the percentages of circulating Treg and Th-17 cels was observed.

It is well known that RA patients have a higher number of Th-17 lymphocytes and lower number of Treg cells in blood compared to healthy controls $[10,11]$. In fact, the imbalance between Th-17 and Treg lymphocytes, where Th-17 lymphocytes seem to be resistant to Treg cells suppression, is a key factor to pathogenic response to autoantibodies $[3,10,11]$. A higher quantity of Treg cells was documented in the inflammed synovium, suggesting once again that Treg are less able to suppress pro inflammatory Th-17 in RA [12]. So, it is possible that joint level MSUS power Doppler may be related to lower activity of synovial (but according to our results, not circulating) Treg lymphocytes. Indeed, synovial Th-17 cells were associated with persistently positive $\mathrm{pD}$ signal in the knee of RA patients [13]. It seems that synovial Th17 and Treg lymphocytes subsets are more important than circulating ones in RA pathogenesis.

In a secondary analysis, we observed higher percentages of Treg cells in patients with clinical low disease activity (LDA). These results are similar to those reported by XX et al., which showed levels of Tregs similar to healthy controls in patients with low disease activity or

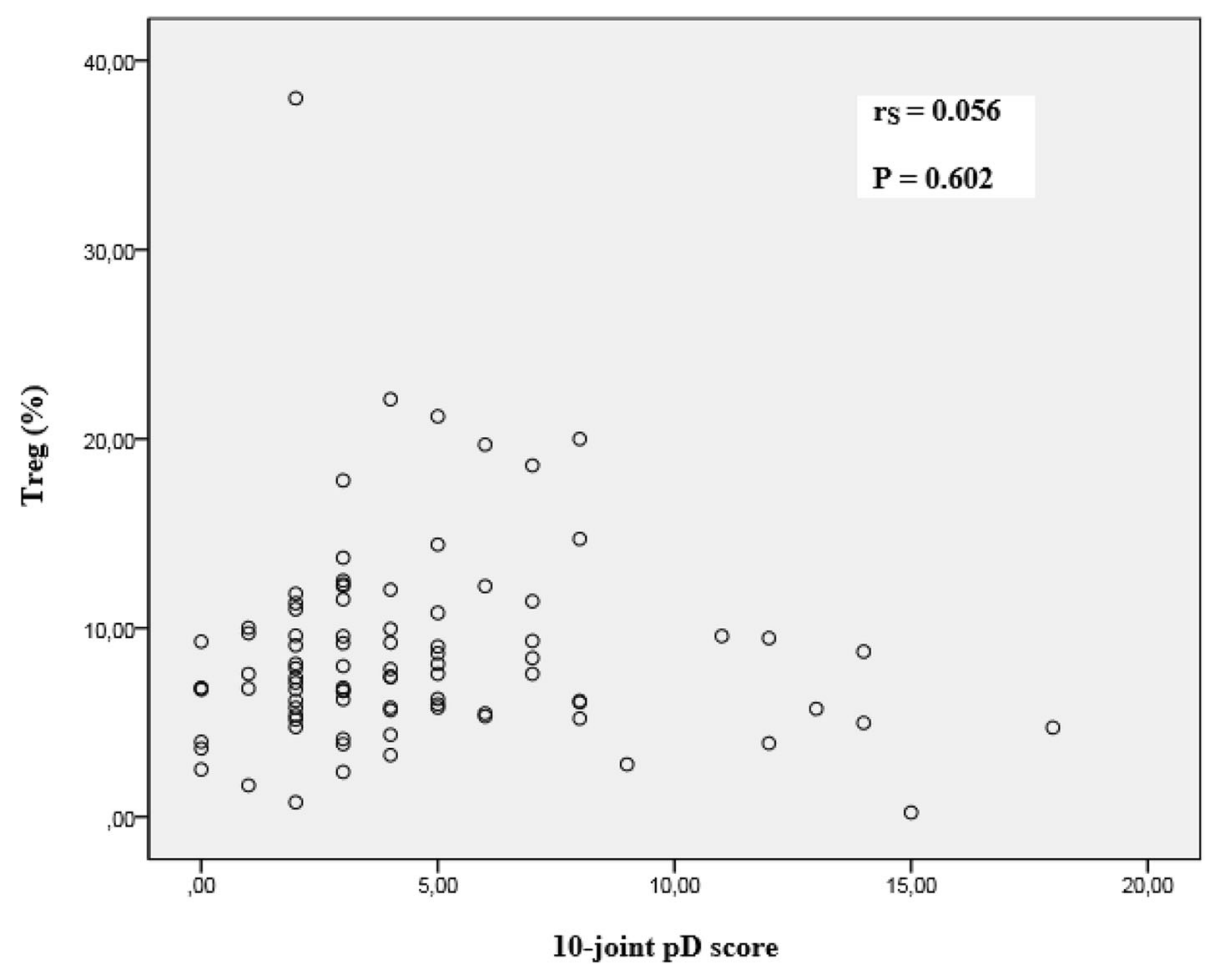

Fig. 1 Association of percentage of Treg cells and 10-joint pD score. ( $r_{S}=$ Spearman correlation coefficient, $\left.n=90\right)$ 
remission [14]. This may possibly reflect a improved Treg/Th-17 balance in patients whose disease is better controlled.

\section{Conclusion}

Our data did not show correlation of inflammatory and structural damage MSUS findings with peripheral blood Treg and Th17 cell profiles in established RA under treatment with non-biologic DMARDs.

\section{Additional files}

Additional file 1: Figure S1. Association of percentage of Th-17 lymphocytes and 10-joint pD score. $\left(r_{s}=\right.$ Spearman correlation coefficient, $n=90)$. (DOC $48 \mathrm{~kb}$ )

Additional file 2: Figure S2. Association of percentage of circulating Treg lymphocytes and grading of power Dopper synovitis (0-3) in the right wrist (Kruskal-Wallis test, $\mathrm{n}=90$ ). (DOC $40 \mathrm{~kb}$ )

Additional file 3: Figure S3. Association of percentage of circulating Th-17 lymphocytes and grading of power Dopper synovitis (0-3) in the right wrist (Kruskal-Wallis test, $\mathrm{n}=90$ ). (DOC $41 \mathrm{~kb}$ )

Additional file 4: Figure S4. Association of percentage of Treg cells and level of disease activity according to DAS28 (Kruskal-Wallis test, $\mathrm{n}=90)$. (DOC $54 \mathrm{~kb}$ )

Additional file 5: Figure S5. Association of percentage of Th-17 lymphocytes and level of disease activity according to DAS28 (Kruskal-Wallis test, $\mathrm{n}=90)$. (DOC $943 \mathrm{~kb}$ )

\section{Acknowledgements}

Not applicable.

\section{Author's contributions}

$A D d P$ and $M C B$ - performed all ultrasound examinations. $M B$ and $A D d P$ performed the statistical analysis, wrote and revised the manuscript. DMP performed all clinical evaluations for the study (DAS 28, HAQ, clinical history). TSB and LP - performed all laboratory work (lymphocyte identification). ADdP, MEB, IGdS, JAM, and HLS - design the study, revised the collected data, revised the literature and revised the final manuscript. All authors read and approved the final manuscript.

\section{Funding}

This work received financial support from the Rheumatology Society of Rio Grande do Sul (SRRS). There was no involvement of the SRRS in the conduction of this study, analysis of data, writing the report or decision to submit the article for publication.

\section{Availability of data and materials}

All laboratory data, clinical data, and ultrasound images are available for consult and are stored by the main author.

\section{Competing interest}

The authors declare they have no financial or non-financial competing interests regarding this work.

\section{Ethics approval and consent to participate}

Local ethics committee approved the study and all patients signed a written informed consent (Ethics Committee Approval number 425:110, on Sep 26th, 2013).

\section{Consent for publication}

Not applicable.

\section{Author details}

${ }^{1}$ Rheumatology Service, Pontifícia Universidade Católica do Rio Grande do Sul (PUCRS), Ipiranga Avenue, 6690 room 220, Porto Alegre, RS CEP 90610-000, Brazil. ${ }^{2}$ Rheumatology Service, Hospital Nossa Senhora da Conceição - Grupo Hospitalar Conceição (GHC), Av. Francisco Trein, 596 2nd floor, Porto Alegre, RS CEP 91350-200, Brazil. '²aboratory of Immunosenescence, Institute of Biomedical Research, Pontificia Universidade Católica do Rio Grande do Sul (PUCRS), Av. Ipiranga, 6690, 2nd floor, Porto Alegre, RS CEP 90610-000, Brazil. ${ }^{4}$ Rheumatology Department, Pontifícia Universidade Católica de Campinas (PUCCAMP), Av. John Boyd Dunlop, S/N, Campinas, SP CEP 13034-685, Brazil.

Received: 28 May 2018 Accepted: 25 June 2019

Published online: 02 July 2019

References

1. Firestein G. Etiology and Pathogenis of rheumatoid arthritis. In: Firestein GS, Budd RC, Gabriel SE, McInnes IB, O'Dell JR, editors. Kelley's textbook of rheumatology. Philadelphia: Saunders; 2013. p. 1059-108.

2. Mclnnes I, Buckley C, Isaacs J. Cytokines in rheumatoid arthritis - shaping the immunological landscape. Nat Rev Rheumatol. 2016;12:63-8.

3. Kima EY, Moudgilb KD. Immunomodulation of autoimmune arthritis by pro-inflammatory cytokines. Cytokine. 2017;98:87-96.

4. Bisi M, do Prado A, Rabelo C, Brollo F, da Silveira I, JA M, et al. Articular ultrasonography: interobserver reliability in rheumatoid arthritis. Rev Bras Reum. 2014:54:250-4.

5. Colebatch A, Edwards C, Østergaard M, van der Heijde D, Balint P, D'Agostino $\mathrm{M}$, et al. EULAR recommendations for the use of imaging of the joints in the clinical management of rheumatoid arthritis. Ann Rheum Dis. 2013;72:804-14.

6. D'Agostino MA, Terslev L, Wakefield R, et al. Novel algorithms for the pragmatic use of ultrasound in the management of patients with rheumatoid arthritis: from diagnosis to remission. Ann Rheum Dis Published Online First: [23 August 2016] doi:https://doi.org/10.1136/annrheumdis2016209646.

7. Baillet A, Gossec L, Paternotte S, Etcheto A, Combe B, Meyer O, et al. Evaluation of serum Interleukin-6 level as a surrogate marker of synovial inflammation and as a factor of structural progression in early rheumatoid arthritis: results from a French National Multicenter Cohort. Arthritis Care Res (Hoboken). 2015;67:905-12.

8. Do Prado AD, Bisi MC, Piovesan DM, Bredemeier M, Batista TS, Petersen L, et al. Ultrasound power Doppler synovitis is associated with plasma IL-6 in established rheumatoid arthritis. Cytokine. 2016;83:27-32.

9. Fazaa A, Ben Abdelghani K, Abdeladhim M, Laatar A, Ben Ahmed M, Zakraoui L. The level of interleukin-17 in serum is linked to synovial hypervascularization in rheumatoid arthritis. Jt Bone Spine. 2014;81:550-1.

10. Wang W, Shao S, Jiao Z. The Th17/Treg imbalance and cytokine environment in peripheral blood of patients with rheumatoid arthritis. Rheumatolol Int. 2012;32:887-93.

11. Niu W, Cai B, Huang Z. Disturbed Th17/Treg balance in patients with rheumatoid arthritis. Rheumatolol Int. 2012;32:2731-6.

12. Jiao Z, Wang W, Jia R, Li J, You H, Chen I. Accumulation of FoxP3-expressing $\mathrm{CD} 4+\mathrm{CD} 25+\mathrm{T}$ cells with distinct chemokine receptors in synovial fluid of patients with active rheumatoid arthritis. Scand J Rheumatol. 2007;36:28-33.

13. Gullick N, Evans H, Church L, Javaraj D, Filer A. Linking power Doppler ultrasound to the presence of Th17 cells in the rheumatoid. PLoS One. 2010;5:e 12516.

14. Chen J, Li J, Gao H, Wang C, Luo J, Lv Z, Li X. Comprehensive evaluation of different T-helper cell differentiation and function in rheumatoid arthritis. J Biomed Biotechnol. 2012. https://doi.org/10.1155/2012/535361.

\section{Publisher's Note}

Springer Nature remains neutral with regard to jurisdictional claims in published maps and institutional affiliations. 